texture. If we feed a rat on tallow, and then open the abdomen, we shall see that the whole of the mesenteric system is full of finely separated and emulsified oil-particles on their way into the blood; and this simple experiment will demonstrate to us the probable result of blocking up this sysiem by cicatrisation or destroying it by inflammation. The slow and often incomplete convalescences from enteric fever, and the liability of its victims to subsequent disease, such as phthisis, is well known. Tubercle in these patients may arise from absorption of cheesy matter from the mesenteric glands into the blood-current; but catarrhal phthisis, and other like sequela, may be due to the imperfect restoration of the fat-collecting machinery. It is to this cause of incomplete convalescence, of marasmus, or of chronic disease as common consequences of enteric fever, that I wish to-day to call the attention of clinical observers. Pathologically, I am not in a position to offer any evidence; but I shall be much indebted to any of my hearers who will secure for me the intestine and mesentery from any case of chronic disease which may seem to have had such an origin as I have ventured to indicate.

\section{ON CATHETERISM OF THE EUSTACHIAN CANAL}

BY R. HIBBERT TAYLOR, M.D.,

Consulting Surgeon to the Eye and Ear Infirmary, Liverpool ; and formerly Lecturer on Ophthalmic Medicine and Surgery in the Royal Infirmary School of Medicine.

CATHETERISATION of the Eustachian canal is no new invention, but one which, like many others in medicine and the arts, was known and adopted in former times, fell into disuse, and has been again revived and practised in our own days.

Upwards of a century ago, a postmaster of Versailles, named Guyot, afflicted with deafness, and probably having some knowledge of anatomy, conceived the idea of treating it by the injection of fluids into the faucial orifice of the Eustachian canal. To effect this, he introduced a bent sound through the mouth, and by this means succeeded in at least washing the entrance of the canal, for it is not likely that he could do more by this method of proceeding, and so relieved his deafness. An account of this invention was submitted to the Academy of Sciences in Paris in the year 1724, but it does not appear to have led to any further result.

Twenty years later, an English surgeon named Cleland, who describes himself as "Surgeon to General Wade's Regiment of Horse", revived the practice, and gave it an important modification by introducing the catheter through the nasal passages instead of the mouth. The instrument which he employed, and which is figured in the Philo. sophical Transactions for $\mathbf{1} 74 \mathbf{I}$, p. 848 , resembles a small catheter, and has this inconvenience, that it is pierced with lateral eyes at its distal extremity, which would give to any fluid injected through it a direction different from that of the Eustachian canal. Although Cleland describes this instrument and the mode of using it, and a syringe which is to be adapteu to it, he does not state that he had used it himself with success. His statement regarding it is as follows. "If, upon trial, the Eustachian canal should be found to be obstructed, the passage is to be lubricated by throwing a little warm water into it by a syringe joined to a flexible silver tube, which is to be introduced through the nose into the oval opening of the duct, at the posterior opening of the nares, towards the arch of the palate. The pipes of the syringe are made small, and of silver, to admit of bending them as occasion offers, and for the most part resemble small catheters."

The surgeons of Montpellier, according to Itard, who wished, on the recommendation of Sauvages, to make use of Cleland's instruments, could not succeed in injecting the canal until they had made some modification in the catheter, probably by substituting a single opening at the extremity for the lateral eyes which Cleland describes. Antoine Petit, in the edition of Palfyn's Anatomy which he published in 175 , does not mention either the memoir or the operation of Cleland; and he criticises the instrument of Guyot as being incapable, as he employed it, of fulfilling the objects which he proposed.

In 1755, Mr. Jonathan Wathen, surgeon in Devonshire Square, London, published in the Philosophical Transactions a short memoir entitled "The Method proposed to restore the Hearing when injured from an Obstruction of the Tuba Eustachiana". In this communica. tion, he remarks that Guyot's proposal to pass a catheter into the Eustachian canal by the mouth is impossible of execution, as any one may convince himself who takes the trouble to examine into the matter. "Convinced of this," he says, "M. Petit proposed, and that learned and skilled anatomist Mr. John Douglas demonstrated, the possibility of passing the probe, etc., through the nose into the Eustachian tube; and this he has continually shown to those who have attended his public lectures; and to him I freely acknowledge myself indebted for the hint by which I was incited to make trial on the living subject of an operation of so much importance to mankind." Wathen made use of a silver pipe of about the size and length of a common probe, to which an ivory syringe was fitted when required. It is somewhat remarkable that Wathen in his paper makes no allusion to Cleland, whose memoir on the same subject was published in the same learned journal only fourteen years previously; but such oversights, whether by accident or intention, are not unknown even in our own times. Wathen appears to have had opportunities of confirming by his own observations those of Tulpius, Valsalva, and Boerhaave, regarding deafness induced by enlargements of the tonsils. He had also noticed a form of deafness brought on by cold and congestion of the Eustachian canal; and further, in a post mortem examination of a man aged 35, who had been deaf during several years as a sequela of cold, and who died of variola, he could not discover any unhealthy condition of the ears, with the exception of obstructed Eustachian canals, induced by the presence of thickened mucus. Building upon these facts, he attempted to inject the Eustachian canals in cases of deafness generally; and of six persons upon whom the operation was practised, five are said to have received more or less benefit from the treatment. The details of one of the most remarkable are as follows. A. had been deaf for eighteen years, and had also an affection of the sight, which consisted in the appearance of a number of different colours floaling continually before his eyes. The deafness was so great that he could hear only one person, with whose voice and appearance he had long been familiar. This patient had been subjected to a variety of treatment, more expensive than efficacious, which had induced salivation and profuse perspiration; but, excepting some slight changes, he had remained in the same condition till February Ist, 1754, when he placed himself under the care of Mr. Wathen. After the first injection made into the Eustachian tube, he heard his own voice, which he was previously unable to do. This injection was followed by four others, at intervals of one or two days. The progress towards amendment continued; and this remarkable phenomenon was induced: when the ear was subjected to sounds as loud as it was accustomed to bear before the deafness commenced, the organ experienced a jarring sensation, a sort of painful grating; and the same thing was observed when the patient spoke. However, he could now hear the voice when moderately elevated, and was able to take part in an ordinary conversation, provided that the room was quiet. It is worthy of remark, that the affection of the sight disappeared after the second injection of the Eustachian tube. This case is certainly remarkable, so far as it goes, considering the long duration and great amount of the deafness. The phenomenon adverted to, with regard to the jarring effect of ordinary sounds upon the restored organ, is one with which all are now familiar who have had frequent occasion to treat diseases of the ear.

The following case, taken from Itard's treatise on Ear-niscases, is both interesting and instructive, although the treatment in this instance was not confined simply to injection of the Eustachian canal.

"Dorothy Paulet, a servant-girl in a farm near Paris, was sent to me by some charitable persons to be treated for deafness, which had reduced her to misery, and rendered her incapable of continuing her service. It was necessary to shout very loud and distinctly into her ears in order to be heard. She had been treated for a long time, and with out benefit, by another practitioner. The external meatus was healthy; the membrane of the tympanum did not present any notable change; and the air, when passed into the Eustachian tube in the ordinary manner, entered the ear; for the patient was conscious of a painful sensation within the organ. In this state of things, the diagnosis was very obscure; and the more so, that there was nothing in the patient's constitution or in the history of her antecedents which could throw any light upon the cause of the deafness. It had commenced two years previously, and had continued to make rapid progress. However, it was necessary, as the girl said, either that she should be cured, or else die of hunger. A motive so urgent induced me to undertake, or rather to attempt, a very hazardous treatment. Moxas upon the head, galvanism, cupping upon the shoulders, strong purgatives, an otitis induced by irritating injections, had no other effect than to weaken and still further discourage this poor girl. At length I decided, almost against myself, to try perforation of the membrane of the tympanum; and I commenced with the right ear. The injection made the next day did not pass through; and it was in vain that I flooded the external meatus by means of a tube of the diameter of a writing-quill, to which a syringe was attached. Three days having been passed in these vain attempts, I then tried to press the injection in another direction-viz., from within outwards through the Eustachian canal. This effort succeeded, for at the second sitting the liquid came through the external 
meatus. It was only at first a sort of transudation; but the next day the water ran drop by drop, and then in a continued jet from the external ear, to the great delight of Dorothy, who perceived almost immediately that she heard much better. The same means, continued during a fortnight, improved considerably the hearing on this side. The result was still more complete on the left side-where, indeed, the deafness was a little less intense. It was not necessary to inject from the faucial extremity of the Eustachian canal. At the third attempt, the liquid flowed from the internal ear into the nostril ; and, to crown our happiness, the wound made in the membrane of the tympanum on that side closed up completely, when the injections were discontinued, after having effected all the good which they could do. To prevent the recurrence of this deafness, I advised the girl to learn to smoke, and to force the tobacco-fumes into the ears by carefully closing the mouth and nostrils."

The following case, also from Itard, shows how the hearing may be improved by the persevering use of injections through the Eustachian canal.

"A lady of Bordeaux, thirty years of age, of lymphatic temperament and very subject to attacks of catarrh, lost her hearing almost entirely, after having suppressed by sea-bathing a leucorrhoal discharge which had existed from puberty. Having been consulted by means of a written statement of her case, I prescribed mild emetics, repeater every fortnight; resinous purgatives ; applications of warm water to the region of the uterus; and finally a blister between the shoulders. These means dispelled the deafness entirely, but only for a few months; at the end of which time, although the leucorrhœa, which had been recalled by the treatment, was as abundant as ever, the deafness returned as before, and accompanied with severe symptoms, which, however, varied in degree; and as these disappeared, there were glairy discharge, thickness of the voice, and snuffling. This lady came to Paris to consult me in the spring of 1813 . On examining the external meatus, I found it so filled with cerumen that I hoped to restore the hearing by the simple removal of this obstruction. In this, however, I was deceived, for it did not produce even a slight improvement ; and the deafness was such, that Mad. - -- could only hear by means of an eartrumpet. The treatment which I had advised during the first attack of this ailment had been repeated unavailingly during this relapse, which decided me to have recourse at once to injection of the Eustachian canal. I employed warm water only, which I first injected into the Eustachian canal of the right ear. The liquid passed in ; but the deafness, instead of being lessened, was so much increased that the sharpest cries and the loudest noises could scarcely be perceived. I was not much annoved at this result, with which I was already familiar, and attributed it to reflux into the cavity of the tympanum of the thickened mucus which obstructed the Eustachian canal. By next morning this increase of deafness had spontaneously disappeared, and Mad. thought that she was even somewhat better-a fact which was no longer doubtful when a second injection had been made. The third produced a still greater change. The sounds of an ordinary voice, provided it was directed towards the concha, were distinctly heard without the aid of a trumpet; and finally, at the end of twelve days of this treatment, the hearing on the right side was completely restored. In order to confirm the cure, I employed about an equal number of injections with sea-water heated to the temperature of an ordinary bath, and forced into the canal in a continuous stream by means of a syringe. I wished next to operate upon the left ear, but encountered an insurmountable difficulty in the narrowness of the left nostril, towards which the septum of the nose was so strongly inclined that it was impossible, after having with difficulty introduced the sound, to pass it onwards so as to place the beak of the instrument in a horizontal position. To escape this difficulty, I proposed to perforate the membrane of the tympanum, and inject the internal ear from without inwards. The patient having consented, the operation caused little pain; but it was not so with the injection, although made with tepid water only. Vertigo came on, with headache and a certain amount of fever. I was obliged to discontinue the injections for six days, although they had only been made twice, and the liquid had not appeared beyond the orifice of the Eustachian canal. When, after the disappearance of these symptoms, I wished to renew the treatment, I perceived that the membrane of the tympanum had healed up; and an injection which I made, in order to assure myself of the fact, left no doubt regarding it, for the water did not penetrate beyond the auditory canal, and did not induce any pain in the ear. This new disappointment made me despair of effecting a cure in this ear; and so I abstained from any further attempt, which, indeed, the patient was little disposed to bear, as the hearing with the right ear was now so complete."

Professor Tröltsch of Würzburg, who has written a treatise on diseases of the ear, as commendable for its brevity as for its clearness and the amount of information which it contains, says that he is in the habit of blowing air through a catheter into the Eustachian canal as a means of diagnosis in certain affections of this tube and of the inner ear ; and from the sounds produced during the passage of the air he is able to form some judgment as to the condition of these parts. $\mathrm{He}$ employs the same method also as a means of cure, and considers it to be useful in clearing the canal of mucus or any other removable obstruction. He says, further, that he has never observed any injury follow the blowing of air into the cavity of the tympanum, but considers the benefit of the air-bath to be in general of a temporary character. The catheter he regards as useful also as a means of applying other remedial agents to the inner ear, as certain gases; and also for the introduction of wires, to cure by electricity. Tröltsch objects to the use of fluids for the purpose of injection into the cavity of the tympanum, as likely to prove injurious; and recommends the employment of air and gases only.

Toynbee does not believe in the utility of the catheter as a means of diagnosis in affections of the inner ear, but recommends a "fad" of his own, in which the patient, closing his mouth and nose, attempts to inflate the Eustachian canal; while the surgeon uses a tube named an "otoscope", one end being inserted into the ear of the patient, and the other into that of the operator. As a means of cure, he thinks with Tröltsch that the catheter may be used in clearing out the Eustachian canal ; but he conveys a caution to use the remedy with gentleness, as fatal effects have followed the sudden and forcible introduction of a stream of air into the cavity of the tympanum. Toynbee relates a case, occurring in his own practice, in which inflation of the Eustachian canal by means of a catheter, in conjunction with other means, effected the cure of deafness.

Wilde of Dublin, in his treatise on Diseases of the Ear, says that he uses the Eustachian catheter as a means of diagnosis when the patient is unable, by closing the mouth and nostrils, to inflate the membrane of the tympanum. He does not believe that washes or vapours, when introduced through the catheter, ever reach the cavity of the tympanum ; and as to the treatment of what is termed " nervous deafness" by injections of ether or anything else, he has no faith in it.

As to the mode of introducing air into the Eustachian canal, Tröltsch and Wilde employ an "air-press"-a machine in which the air, after being forced into a strong cylinder, is gradually introduced by turning a stopcock into a tube communicating with the catheter, and so into the Eustachian canal. This mode requires the use of a rather complicated apparatus, and, besides, is open to the objection of possibly admitting a strong current of air to flow suddenly into the ear ; and, if the point of the catheter slip from the opening of the canal, the air may be driven into the cellular membrane of the throat or directly into the larynx-an accident which is supposed to have happened in one of the fatal cases which occurred in London some years ago.

The cases above recorded as having occurred in the practice of Wathen and Itard, if worthy of credit-and I see no reason why they should be called in question-sufficiently attest the benefit which may in some instances be derived from injection of the Eustachian canal with tepid fluid, and appear to controvert the statement of Wilde that fluids so introduced can never reach the cavity of the ear. They afford, at all events, sufficient grounds for making trial of this mode of treatment in any case in which there is reason to suspect occlusion of the Eustachian, as evidenced by the patient's inability to inflate the membrane of the tympanum. My own experience-which, however, has not been very extensive in catheterism of the canal-would certainly incline me to this decision. I have observed benefit to result in several instances from inflation of the Eustachian by blowing air into it through a catheter. The introduction of the instrument into the faucial orifice of the canal is by no means difficult, requiring, no doubt, the possession of a certain amount of dexterity, which, however, lies within the compass of almost any one to obtain; and, as I think the air is best introduced by applying the mouth to the wide end of the catheter and blowing through it with varying force, all complicated apparatus is thus dispensed with, and the operation is neither alarming to the patient nor unreasonably difficult to the operator. I have not myself tried the injection of water or any other liquid into the Eustachian by means of a catheter; but I see no valid reason why it should not be done, if conducted with caution; and, by means of a moderate sized syringe fitted by its nozzle to the wide extremity of the catheter, it could be effected without difficulty.

In conclusion, I beg to commend the subject to the consideration of my brethren in the profession. It seems to merit their attention; for a mode of treatment which, in the hands of others, has in some instances been productive of such excellent results, may not improbably, in similar cases, prove equally successful in theirs. 